\title{
The route of exploration to inherit and carry forward Dunhuang culture
}

\author{
Guanggen Li \\ The Party School of Gansu Provincial committee of CPC \\ 1157501103@qq.com, China.
}

Keywords: Dunhuang culture, modern dissemination, route exploration.

\begin{abstract}
Dunhuang achieves remarkable results in the field of academic research and cultural heritage protection, but there has larger development space in the heritage of Dunhuang culture. Article start from the analysis of the Worldwide of Dunhuang culture, describes the status of the spread of Dunhuang culture. Meanwhile proposes and summarizes the way and model of inheriting and carrying forward Dunhuang culture, and the protection measures of Dunhuang culture need to be discussed.
\end{abstract}

\section{The brief introduction of Dunhuang culture}

In the process of five thousand-year Chinese civilization, from the seclusion to opening up, from the conflict to foreign culture to the culture globalization, China aborts and contacts the foreign culture not only to promote the innovation and develop the Chinese culture, but also gain a great contribution to the development of the civilization of world. Dunhuang, located in the throat of Silk Road, blending the essence of Chinese and foreign cultures, creating a resplendent Buddhist grotto art, left the great cultural heritage which worth later generations to study and explore. Dunhuang culture is a special regional culture which is formed by the intersection of different cultures. It not only has regional, but also has national and cosmopolitan. Grottoes, sculptures, murals, architectural heritage of Dunhuang is very rich, more than 10000 pieces of cultural relics collection, saving the 3000 painted body, 45000 square meters of murals from 735 caves which belong to 4 to 14 century, more than. It is the largest art treasure house of the world. The history of the Dunhuang culture is long, well preserved, the high artistic value of the world, and each piece of art has a deep brand of foreign culture and Chinese culture collision, blend of traces ${ }^{[1]}$. However, facing globalization impact and world political, economic, and cultural and other aspects today, inheritance promoting Dunhuang culture becomes imperative.

\section{The status of the spread of Dunhuang culture}

For a long time, The administrator and researcher of the Dunhuang heritage have made outstanding contributions to the protection of the culture of Dunhuang, monitoring, digital, visitor management and many other techniques among the world series, and in the Dunhuang culture propagation has slightly inferior. Esthetician Ye Lang believes that to promote the spirit of Chinese traditional culture in the contemporary revival, obtained in response to the problems in today's era of enlightenment and methods from China's traditional culture, the spirit of Chinese traditional culture into the contemporary life ${ }^{[2]}$. How to further narrow the gap between the Dunhuang cultural distance from the contemporary society, how to enhance scene perception and experience level of the tourist, how to make the Dunhuang culture to "live" up shine with brilliance of the times, is the need of Dunhuang study, pay attention to the conservation and management of cultural heritage and social all circles, completed the mission of the times.

Currently, the heritage of Dunhuang culture needs to solve several issues: First, to further resolve the Dunhuang culture. At present, Dunhuang scholar's main focus is mainly concentrated on academic research and heritage protection work, in detail on the heritage of the contemporary deficient input must be public to listen to understand the language and forms of cultural heritage. Second, to further solve the good modern communication, with the development of Internet and new media and need to develop new media communication, Changing the traditional and single mode of cultural transmission, 
With the help of new media means that Dunhuang culture to the audience love to see and hear expression of contemporary people into the field of culture, educate the people in a subtle influence, Let the contemporary people recognition, identification, close to the culture of Dunhuang. Third: Further to solve the problem of the aesthetic carrier of Dunhuang culture. At present, the aesthetic value of Dunhuang culture, Dunhuang Art lack and contemporary people life is closely related to the aesthetic carrier must be Dunhuang culture into a comprehensive system of aesthetic education of the contemporary people, landscape environment, daily aesthetic activities and consumption, in the form of products into the contemporary people's way of life, guide the pursuit of the spirit, enhance the realm of life, the pursuit of values. Completed from region to the world and make Dunhuang culture back to the world cultural system ", in the world cultural dialogue and exchanges play a positive role, continuous to world output are interwoven and interdependent", "beauty of beauty, beauty and harmony, beauty and harmony of the world" ideological power steering ${ }^{[3]}$.

\section{Explore the route of developing Dunhuang culture}

Cultural heritage is the carrier of the traditional culture and the source of human thought. Heritage and promote the traditional culture is our own responsibility. In the face of the spread of the cultural status of Dunhuang, to reach a deeper and more extensive dissemination purposes, you can proceed from the following aspects:

\subsection{Dissemination of literary channels}

The accumulation of the literary arts is the accumulation of the historical culture, the literature dissemination way is extremely important; literature education is also an integral part of the whole education system. Therefore, Dunhuang culture needs the dissemination of the literary genre to achieve better effect. The Dunhuang caves themselves recorded many paintings, literature books, sculpture art, etc., thus can spread the precious fruits of ancient times through the literature way. For example, Dunhuang murals themselves record many Buddhist stories, nine color deer, xianghu and Jinxiang, so, we can promote Dunhuang culture's spreading according to Dunhuang murals material, the preparation of the classical literary works of different cultural background, illustrated tells story of Dunhuang murals. Chinese and foreign literatures do a large number of literary creations of Dunhuang and form a presented in the form of literature of Dunhuang. Japanese writer Inoue Yasushi in 1950 April published short story "paint pot bottle" as first foreign literature. In China, for more than a hundred years, many domestic scholars have written many travel notes or essays about Dunhuang's history and cultural relics after travels in Dunhuang. "Dunhuang impression" and "beauty of Dunhuang" can understand all features of Dunhuang. (See Figure 1 and figure 2).

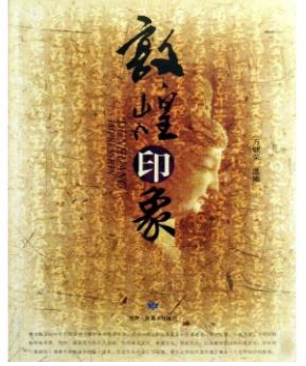

Fig. 1 Dunhuang impression

\subsection{Education transmission way}

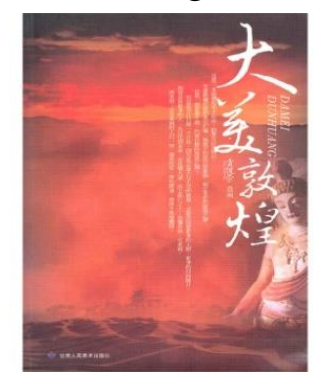

Fig. 2 beauty of Dunhuang

The implementation of the cultural education system in Dunhuang, Deepen the reform of education system, Improve the cultural and educational mechanism of China, the Dunhuang culture and education to fully integrate the whole process of the national education system, as to promote innovation, promote the socialist core value system, as the popularity of Dunhuang culture and lay a solid foundation. Increase the professional culture and art colleges of Dunhuang culture, Dunhuang art education efforts, through the creation of Dunhuang Cultural History, art history of Dunhuang, Dunhuang music, dance, painting and so on professional art undergraduate or graduate student curriculum, proportion of improve the culture of Dunhuang, Dunhuang Art in professional college 
education, to guide the students, Dr. students to Dunhuang culture, Dunhuang art for the project to carry out master's thesis and doctoral dissertation writing. For all types of University, to carry out lectures on Dunhuang culture, Dunhuang Art lecture course, let students to get close to the traditional culture, identity cultural traditions, the Dunhuang culture to fully integrate the educational system for primary and secondary students, the creation of Dunhuang art appreciation etc. art curriculum, guide teenagers perceived Dunhuang culture, artistic beauty, enhance artistic accomplishment, improve personal values.

\subsection{Active route communication}

In literary and artistic creation of Gansu, drama "the Silk Road Flower Rain" is a milestone in the National Ballet of China. It is the first established brand of Dunhuang culture, having a significant impact in the domestic and the world (See Figure 3 and Figure 4). The drama to sing the praises of the friendship between Chinese people and foreign people as the theme, inclusive interpretation of Dunhuang culture, the openness of the Silk Road; created a fresh and rare Dunhuang dance series in the novel and unique language of dance. The drama is still the Dunhuang mural in the dance image into three-dimensional, full of vitality of the stage image, in terms of the development of Chinese dance art made the contribution of innovation, excellence, and gains a number of awards and art circles at home and abroad caused great repercussions. In recent years, the "dream of Dunhuang", "Dunhuang rhyme" Dunhuang culture background of song and dance repertoire by popular (See Figure 5 and Figure 6).

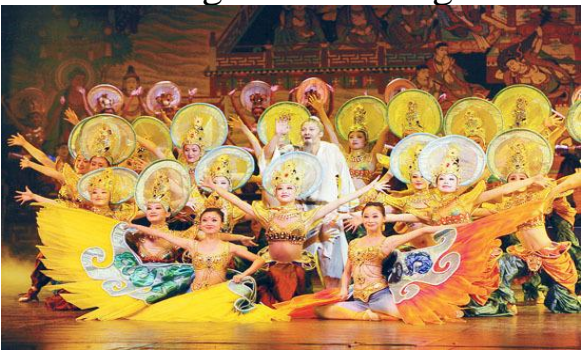

Fig. 3 " the Silk Road Flower Rain ".

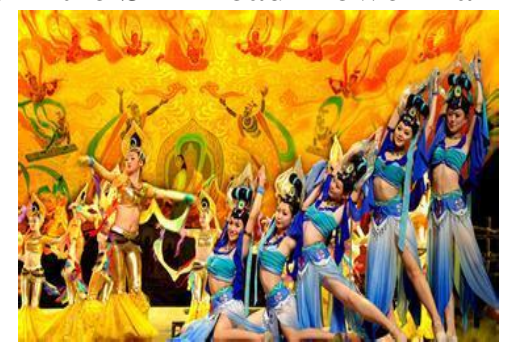

Fig. 5 " dream of Dunhuang ".

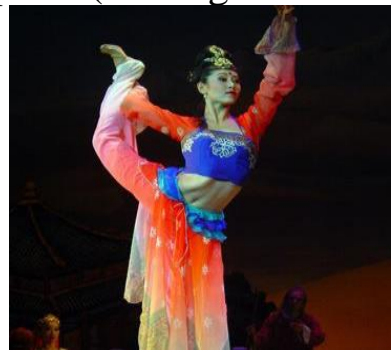

Fig. 4 " the Silk Road Flower Rain ".

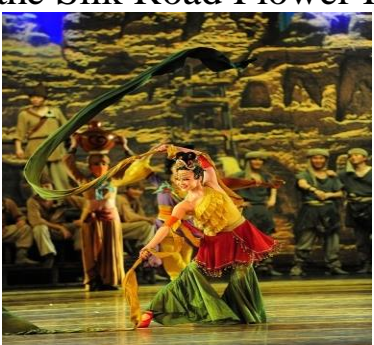

Fig. 6 "Dunhuang dream".

\subsection{The development and dissemination of art products}

Dunhuang, in the background of its brilliant history, has a very rich artistic product, but the most of the artistic products are only tourism souvenirs. Actually, Dunhuang culture background of the art of owns products to achieve the propaganda effect, is not to be underestimated to make the Dunhuang culture better communication. We wish to combine the art product sales to overseas, such as cave paintings simulation stereotype, small Guanyin Buddha sculpture, mural compilations and various exquisite craft ornaments and so on. I believe that in the context of the Chinese hot, these products will be welcomed and achieved the purpose of spreading the culture of Dunhuang.

\section{5 media publicity and communication}

The emerging media has received unprecedented development in recent years, in addition to the mass media such as broadcasting, television, newspapers and so on, as well as many new media, such as mobile phone and network. The information on the large capacity of the network, let people in the home understand information updating and to study the changes in the history of Dunhuang. Therefore, the media of Dunhuang culture can start from above means of using multimedia combination way, Propaganda and reports on the culture of Dunhuang to report on related activities and performances in time. And can consider the form of the subject of the Dunhuang culture. So as to rely on the media to spread the Dunhuang culture widely 


\subsection{Build Dunhuang cultural brand communication}

Actively plan to hold the Dunhuang Cultural Forum, Discussion on the formation of the Dunhuang culture in the inner and outside world of the world, Create cultural exchange. Planning to organize regular seminars, Invite politicians, cultural circles, fashion elite, celebrity participation, appreciation, assessment of Dunhuang dance, music, painting, Buddhist art, etc. Continue to introduce Dunhuang culture theme exhibition, with the help of modern means of science and technology and innovative design strength, to spread with Dunhuang history, Dunhuang culture digital display, Dunhuang lifestyle and other topics, to show the results of the combination of Dunhuang culture and modern life style, Pass Dunhuang cultural spirit and value pursuit. Actively encourage the theme of the historical and cultural Dunhuang film, television drama, micro film, animation, drama, literature and other forms of literary creation, Taking literary and artistic works as the effective carrier for the spread of cultural brand in Dunhuang Actively rely on the Internet, social networking sites, microblogging, micro channel and other modern communication platform, Form the mass communication of Dunhuang culture.

\subsection{Build Dunhuang characteristic landscape design}

The accumulation of history and culture is the basis of city full of characteristics, City Square, sculpture, landmark building, historic block and other city characteristic space as the accumulation of history and culture, can shape and strengthen the city characteristic, it is the unique value of the media and carrier to the outside world. Therefore, we should protect the cultural connotation of the city, On the basis of protecting good places of interest, we should grasp the connotation of the regional culture and the connotation of the city landscape design., Make the city both context and features. Depending on the feature layout, cultural resources endowment and spatial features of different city area, to create the cultural landscape area with each characteristic Through the construction of a series of historical and cultural theme Plaza, the theme park, cultural theme will be important to be concentrated display, and urban leisure space, public buildings and combination of history and culture exhibition at the core nodes.

\section{Summary}

In short, carrying forward the Dunhuang culture needs to make strategic deployment from the national level, comprehensive community strength, the full range of marketing and dissemination of the Dunhuang culture relying on the emerging media, technology, social support, from the surface to the deep exploration,. Bring the prosperity of the cultural brand in Dunhuang in the premise of following the cultural identity and realizing the international influence communication; eventually create a "Dunhuang model" with the traditional culture and the modern revival of the traditional culture and the development of the finance, the culture traveling and the landscape design in the research.

\section{References}

[1]. Jianjiang Wang. Dunhuang culture, art and aesthetics under the background of globalization. Journal of Northwest Normal University. (2004) No.6.

[2]. Lang Ye. 21 century, China will affect the world in the spirit. Chinese culture. 2013-7-29, P. 3

[3]. Xiaotong Fei. The thoughts of "good society". Xiaotong Fei on cultural and cultural consciousness. Beijing: Qunyan press. 2005, P. 127-132. 